\title{
Clinical Characteristics and Outcomes of Very Elderly Patients With Atrial Fibrillation at High Bleeding Risk
} - The Fushimi AF Registry -

\author{
Yuya Ide, MD, PhD; Hisashi Ogawa, MD; Kenjiro Ishigami, MD; Syuhei Ikeda, MD; \\ Kosuke Doi, MD; Yasuhiro Hamatani, MD, PhD; Akiko Fujino, MD; \\ Yoshimori An, MD, PhD; Mitsuru Ishii, MD, PhD; Moritake Iguchi, MD, PhD; \\ Nobutoyo Masunaga, MD; Masahiro Esato, MD, PhD; Hikari Tsuji, MD, PhD; \\ Hiromichi Wada, MD, PhD; Koji Hasegawa, MD, PhD; Mitsuru Abe, MD, PhD; \\ Gregory Y.H. Lip, MD; Masaharu Akao, MD, PhD for the Fushimi AF Registry Investigators
}

\begin{abstract}
Background: The ELDERCARE-AF trial demonstrated that low-dose edoxaban prevented stroke or systemic embolism (SE) in very elderly Japanese patients with non-valvular atrial fibrillation (NVAF) in whom standard oral anticoagulant therapy was inappropriate because of high bleeding risk. The aim of this study was to elucidate the characteristics and outcomes of such patients in routine clinical practice.
\end{abstract}

\begin{abstract}
Methods and Results: Data were extracted from the Fushimi AF Registry for ELDERCARE-eligible NVAF patients aged $\geq 80$ years, with a $\mathrm{CHADS}_{2}$ score $\geq 2$ and $\geq 1$ bleeding risk factors, as shown in the ELDERCARE-AF trial. ELDERCARE-eligible patients ( $n=549$; $12.8 \%$ of the entire cohort, $52.9 \%$ of those aged $\geq 80$ years and with $\mathrm{CHADS}_{2}$ score $\geq 2$ ) were less often male, were older, had more comorbidity and higher risk scores than non-eligible patients from the entire cohort $(n=3,734)$. The crude incidence $(\%$ per patientyear) of adverse events was significantly higher in ELDERCARE-eligible than non-eligible patients (stroke/SE, 4.8\% vs. $2.0 \%$; major bleeding, $3.6 \%$ vs. $1.9 \%$; all-cause mortality, $15.5 \%$ vs. $3.9 \%$; cardiovascular death, $2.7 \%$ vs. $0.6 \%$; all log-rank $\mathrm{P}<0.001$ ). Compared with non-eligible patients aged $\geq 80$ years and with a CHADS 2 score $\geq 2(n=488)$, the incidence of stroke/SE, all-cause mortality, and cardiovascular death remained significantly higher in ELDERCARE-eligible patients.
\end{abstract}

Conclusions: Patients with NVAF who met the inclusion criteria of the ELDERCARE-AF trial were common in routine clinical practice, and had poor clinical outcomes.

Key Words: Atrial fibrillation; Bleeding risk; Very elderly

$\mathbf{E}$ lderly patients with non-valvular atrial fibrillation (NVAF) have a high risk of thromboembolism, such as stroke and systemic embolism (SE), with increasing age; in these patients, oral anticoagulant (OAC) therapy is beneficial. ${ }^{1-3}$ Current clinical guidelines recommend that these patients receive OAC therapy to prevent stroke, ${ }^{\mathbf{4 6}}$ but NVAF patients at high risk of stroke are also at high risk of serious bleeding, and OACs tend to be withheld in such patients because of high bleeding risks. ${ }^{7}$
The ELDERCARE-AF (Edoxaban Low-Dose for Elder Care Atrial Fibrillation Patients) trial demonstrated that low-dose edoxaban $(15 \mathrm{mg}$, once daily) prevented stroke or SE in very elderly ( $\geq 80$ years) Japanese patients with NVAF who were considered inappropriate for standard OAC therapy due to bleeding risk (i.e., low creatinine clearance $[15-30 \mathrm{~mL} / \mathrm{min}]$, a history of bleeding from a critical area or organ, low body weight $[\leq 45 \mathrm{~kg}]$, continuous use of non-steroidal anti-inflammatory drugs [NSAIDs],

Received September 3, 2021; accepted September 3, 2021; J-STAGE Advance Publication released online October 16, 2021 Time for primary review: 1 day

Department of Cardiology (Y.I., H.O., K.I., S.I., K.D., Y.H., A.F., Y.A., M. Ishii, M. Iguchi, N.M., M. Abe, M. Akao), Division of Translational Research (H.W., K.H.), National Hospital Organization Kyoto Medical Center, Kyoto; Department of Arrhythmia, Ogaki Tokushukai Hospital, Gifu (M.E.); Tsuji Clinic, Kyoto (H.T.), Japan; Liverpool Centre for Cardiovascular Science, University of Liverpool, Liverpool (G.Y.H.L.); Liverpool Heart and Chest Hospital, Liverpool (G.Y.H.L.), UK; and Aalborg Thrombosis Research Unit, Department of Clinical Medicine, Aalborg University, Aalborg (G.Y.H.L.), Denmark

The last two authors are joint senior authors (G.Y.H.L., M. Akao).

Mailing address: Masaharu Akao, MD, PhD, Department of Cardiology, National Hospital Organization Kyoto Medical Center, 1-1 Mukaihata-cho, Fukakusa, Fushimi-ku, Kyoto 612-8555, Japan. E-mail: akao@kuhp.kyoto-u.ac.jp

All rights are reserved to the Japanese Circulation Society. For permissions, please e-mail: cr@j-circ.or.jp

ISSN-2434-0790 
A

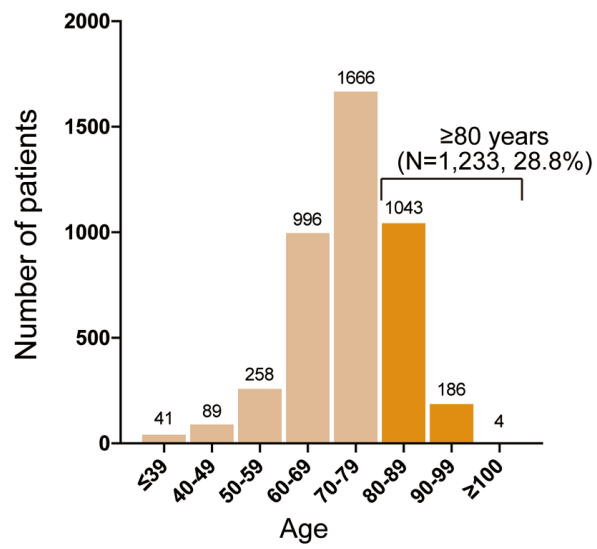

B

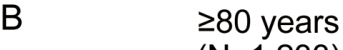

$(\mathrm{N}=1,233)$

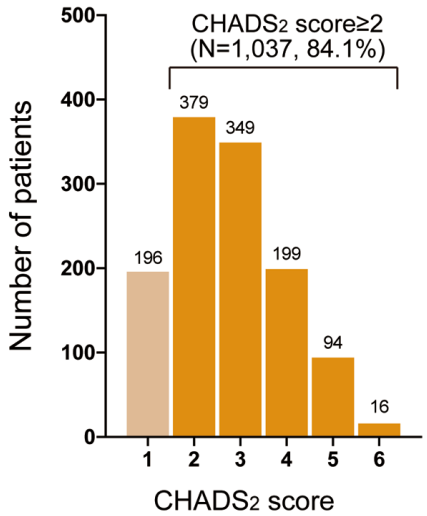

C $\quad \geq 80$ years and $\mathrm{CHADS}_{2}$ score $\geq 2$

$(\mathrm{N}=1,037)$

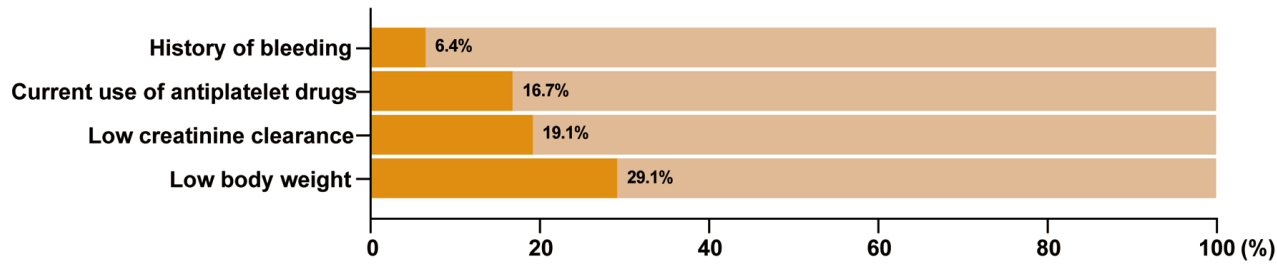

D

ELDERCARE eligible patients ( $N=549)$

Entire cohort $(\mathrm{N}=4,283)$

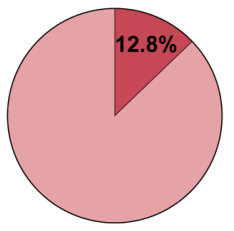

$\geq 80$ years and $\mathrm{CHADS} 2$ score $\geq 2(\mathrm{~N}=1,037)$

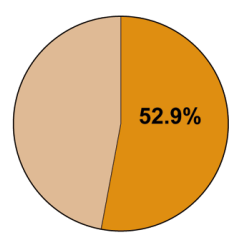

$\square$ ELDERCARE eligible

$\square$ Non-eligible

Figure 1. Distribution of ELDERCARE-eligible patients. (A) Age distribution in the entire cohort of patients with non-valvular atrial fibrillation. (B) Distribution of $\mathrm{CHADS}_{2}$ scores in patients aged $\geq 80$ years. (C) Proportion of patients with bleeding risk factors among those aged $\geq 80$ years with a $\mathrm{CHADS}_{2}$ score $\geq 2$. (D) Proportion of ELDERCARE-eligible patients in the entire cohort (Left) and among those aged $\geq 80$ years with a $\mathrm{CHADS}_{2}$ score $\geq 2$ (Right).

or current use of an antiplatelet drug), without significantly increasing the risk of major bleeding compared with placebo. ${ }^{8}$ Therefore, low-dose edoxaban may be a feasible anticoagulant treatment for elderly NVAF patients at bleeding risk, rather than leaving such patients untreated with no antithrombotic therapy.

In contemporary routine community-based practice, the clinical characteristics and outcomes of such patients, who are eligible for the ELDERCARE-AF trial, are unclear. The objective of the present study was to investigate the characteristics and outcomes of very elderly Japanese NVAF patients with bleeding risk using the data from a largescale, community-based prospective survey of Japanese AF patients, namely the Fushimi AF Registry.

\section{Methods}

\section{Study Population}

The detailed study design, patient enrollment, definitions of measurements, and baseline clinical characteristics of patients in the Fushimi AF Registry (University Hospital Medical Information Network [UMIN] Clinical Trials Registry ID: UMIN000005834; http://www.umin.ac.jp/ctr/ index.htm) have been described elsewhere.9,10 The inclusion criterion for the Registry is documentation of atrial fibrillation (AF) on a 12-lead electrocardiogram or Holter mon- 


\begin{tabular}{|c|c|c|c|c|c|c|}
\hline & $\begin{array}{l}\text { ELDERCARE } \\
\text { eligible } \\
(n=549)\end{array}$ & $\begin{array}{c}\text { Non-eligible } \\
\text { (entire cohort; } \\
n=3,734)\end{array}$ & $P$ value $A$ & $\begin{array}{c}\text { Non-eligible } \\
\text { ( } \geq 80 \text { years, } \\
\text { CHADS } 2 \geq 2 ; \\
n=488)\end{array}$ & P value ${ }^{B}$ & $\begin{array}{c}\text { ELDERCARE- } \\
\text { AF trialc } \\
\text { (all patients; } \\
n=984 \text { ) }\end{array}$ \\
\hline Age (years) & $86.2 \pm 4.8$ & $71.4 \pm 10.2$ & $<0.001$ & $84.1 \pm 3.7$ & $<0.001$ & $86.6 \pm 4.2$ \\
\hline Male sex & $176(32.1)$ & $2,417(64.7)$ & $<0.001$ & $279(57.2)$ & $<0.001$ & $419(42.6)$ \\
\hline Type of AF & & & 0.063 & & 0.362 & \\
\hline Paroxysmal & $254(46.3)$ & $1,886(50.5)$ & & $212(43.4)$ & & $463(47.1)$ \\
\hline Sustained & $295(53.7)$ & $1,848(49.5)$ & & $368(56.6)$ & & $521(52.9)$ \\
\hline Body weight $(\mathrm{kg})$ & $46.8 \pm 10.3$ & $61.6 \pm 12.8$ & $<0.001$ & $58.6 \pm 8.7$ & $<0.001$ & $50.6 \pm 11.0$ \\
\hline BMI $\left(\mathrm{kg} / \mathrm{m}^{2}\right)$ & $20.4 \pm 3.5$ & $23.6 \pm 4.0$ & $<0.001$ & $23.8 \pm 3.3$ & $<0.001$ & $22.1 \pm 3.7$ \\
\hline History of stroke/SE & $188(34.2)$ & $661(17.7)$ & $<0.001$ & $120(24.6)$ & $<0.001$ & $\mathrm{~N} / \mathrm{A}$ \\
\hline History of stroke & 175 (31.9) & $585(15.7)$ & $<0.001$ & $112(23.0)$ & 0.001 & $236(24.0)$ \\
\hline History of SE & $11(2.0)$ & $41(1.1)$ & 0.091 & $5(1.0)$ & 0.219 & $\mathrm{~N} / \mathrm{A}$ \\
\hline Pre-existing heart failure & $291(53.0)$ & 855 (22.9) & $<0.001$ & $193(39.6)$ & $<0.001$ & $533(54.2)$ \\
\hline Hypertension & $408(74.3)$ & $2,293(61.4)$ & $<0.001$ & $384(78.7)$ & 0.098 & $810(82.3)$ \\
\hline Diabetes & $119(21.7)$ & $894(23.9)$ & 0.243 & $137(28.1)$ & 0.017 & 225 (22.9) \\
\hline Dyslipidemia & $234(42.6)$ & $1,670(44.7)$ & 0.355 & $213(43.7)$ & 0.734 & $\mathrm{~N} / \mathrm{A}$ \\
\hline Coronary artery disease & $177(32.2)$ & $453(12.1)$ & $<0.001$ & $41(8.4)$ & $<0.001$ & $257(26.1)$ \\
\hline Peripheral artery disease & $44(8.0)$ & $132(3.5)$ & $<0.001$ & $14(2.9)$ & $<0.001$ & $\mathrm{~N} / \mathrm{A}$ \\
\hline Chronic kidney disease & $346(63.0)$ & $1,188(31.8)$ & $<0.001$ & $235(48.2)$ & $<0.001$ & $\mathrm{~N} / \mathrm{A}$ \\
\hline Calculated $\mathrm{CrCl}(\mathrm{mL} / \mathrm{min})$ & $33.0 \pm 16.0$ & $59.7 \pm 33.3$ & $<0.001$ & $48.0 \pm 15.7$ & $<0.001$ & $36.3 \pm 14.4$ \\
\hline COPD & $34(6.2)$ & $197(5.3)$ & 0.374 & $28(5.7)$ & 0.758 & $\mathrm{~N} / \mathrm{A}$ \\
\hline $\mathrm{CHADS}_{2}$ score & $3.2 \pm 1.1$ & $1.8 \pm 1.3$ & $<0.001$ & $2.9 \pm 1.0$ & 0.003 & $3.1 \pm 1.1$ \\
\hline $\mathrm{CHA}_{2} \mathrm{DS}_{2}$-VASc score & $5.1 \pm 1.2$ & $3.1 \pm 1.6$ & $<0.001$ & $4.4 \pm 1.1$ & $<0.001$ & $4.9 \pm 1.3$ \\
\hline HAS-BLED score & $2.4 \pm 1.0$ & $1.6 \pm 1.0$ & $<0.001$ & $1.9 \pm 0.9$ & $<0.001$ & $2.3 \pm 0.9$ \\
\hline \multicolumn{7}{|l|}{ Prescription at baseline } \\
\hline Oral anticoagulant & $268(48.8)$ & $2,084(55.8)$ & 0.002 & 301 (61.7) & $<0.001$ & $\mathrm{~N} / \mathrm{A}$ \\
\hline Warfarin & 219 (39.9) & $1,506(40.3)$ & 0.853 & $213(43.7)$ & 0.25 & $N / A$ \\
\hline DOAC & $49(8.9)$ & $578(15.5)$ & $<0.001$ & $88(18.0)$ & $<0.001$ & N/A \\
\hline Antiplatelet drug ${ }^{\mathrm{D}}$ & $249(45.3)$ & $902(24.2)$ & $<0.001$ & $109(22.3)$ & $<0.001$ & $\mathrm{~N} / \mathrm{A}$ \\
\hline Anti-arrhythmic drug & $48(8.7)$ & $803(21.5)$ & $<0.001$ & $62(12.7)$ & 0.042 & $\mathrm{~N} / \mathrm{A}$ \\
\hline ACEI/ARB & $285(51.9)$ & $1,611(43.4)$ & $<0.001$ & $245(50.2)$ & 0.522 & $\mathrm{~N} / \mathrm{A}$ \\
\hline Calcium channel blocker & $166(30.2)$ & $1,182(31.7)$ & 0.51 & $180(36.9)$ & 0.027 & $\mathrm{~N} / \mathrm{A}$ \\
\hline Diuretics & $281(51.2)$ & $2,783(74.5)$ & $<0.001$ & $299(61.3)$ & 0.002 & $\mathrm{~N} / \mathrm{A}$ \\
\hline Statins & $155(28.2)$ & $900(24.1)$ & 0.035 & $120(24.6)$ & 0.168 & $\mathrm{~N} / \mathrm{A}$ \\
\hline \multicolumn{7}{|l|}{ Bleeding risk factors ${ }^{\mathrm{E}}$} \\
\hline Low body weight & $302(55.0)$ & $265(7.1)$ & $<0.001$ & & & $374(38.0)$ \\
\hline Low $\mathrm{CrCl}$ & $198(36.1)$ & $96(2.6)$ & $<0.001$ & & & $403(41.0)$ \\
\hline Use of antiplatelet drugs & $173(31.5)$ & $335(9.0)$ & $<0.001$ & & & $529(53.8)$ \\
\hline History of bleeding & $66(12.0)$ & $131(3.5)$ & $<0.001$ & & & $222(22.6)$ \\
\hline
\end{tabular}

Unless indicated otherwise, data are given as the mean \pm SD or $n(\%)$. ${ }^{A} E L D E R C A R E$ eligible vs. non-eligible (entire cohort). ${ }^{B} E L D E R C A R E$ eligible vs. non-eligible (aged 80 years, $\mathrm{CHADS}_{2}$ score $\geq 2$ ). ${ }^{\mathrm{C} D a t a}$ from are from Okumura et al. ${ }^{8}$ DPatients receiving antiplatelet drugs for any reason. EAmong the bleeding risk factors, low body weight was defined as body weight $\leq 45 \mathrm{~kg}$, low creatinine clearance (CrCl) was defined as $15 \mathrm{~mL} / \mathrm{min} \leq \mathrm{CrCl}<30 \mathrm{~mL} / \mathrm{min}$, the use of antiplatelet drugs was for the treatment of concomitant coronary artery disease or peripheral artery disease, and a history of bleeding was for bleeding from a critical area or organ. ACEI, angiotensin-converting enzyme inhibitor; AF, atrial fibrillation; ARB, angiotensin receptor blocker; BMI, body mass index; COPD, chronic obstructive pulmonary disease; DOAC, direct oral anticoagulant; N/A, not available; SE, systemic embolism.

itoring at any time. There were no exclusion criteria. In all, 81 institutions in the Fushimi district in Kyoto, Japan, participated in the Registry. Patient enrollment in the Registry started from March 2011. Follow-up data were primarily collected by reviewing inpatient and outpatient medical records, with additional follow-up information collected by contacting patients, their relatives, and/or referring physicians by mail or telephone. The study protocol conformed to the ethical guidelines of the 1975 Declaration of Helsinki, and was approved by the ethics committees of the National Hospital Organization Kyoto Medical Center and Ijinkai Takeda General Hospital. Because the present research is part of an observational study not using human biological specimens, written informed consent was not obtained from each patient according to the ethical guidelines for epidemiological research issued by Ministry of Education, Culture, Sports, Science and Technology and Ministry of Health, Labour and Welfare, Japan.

The present study enrolled "ELDERCARE-eligible" 

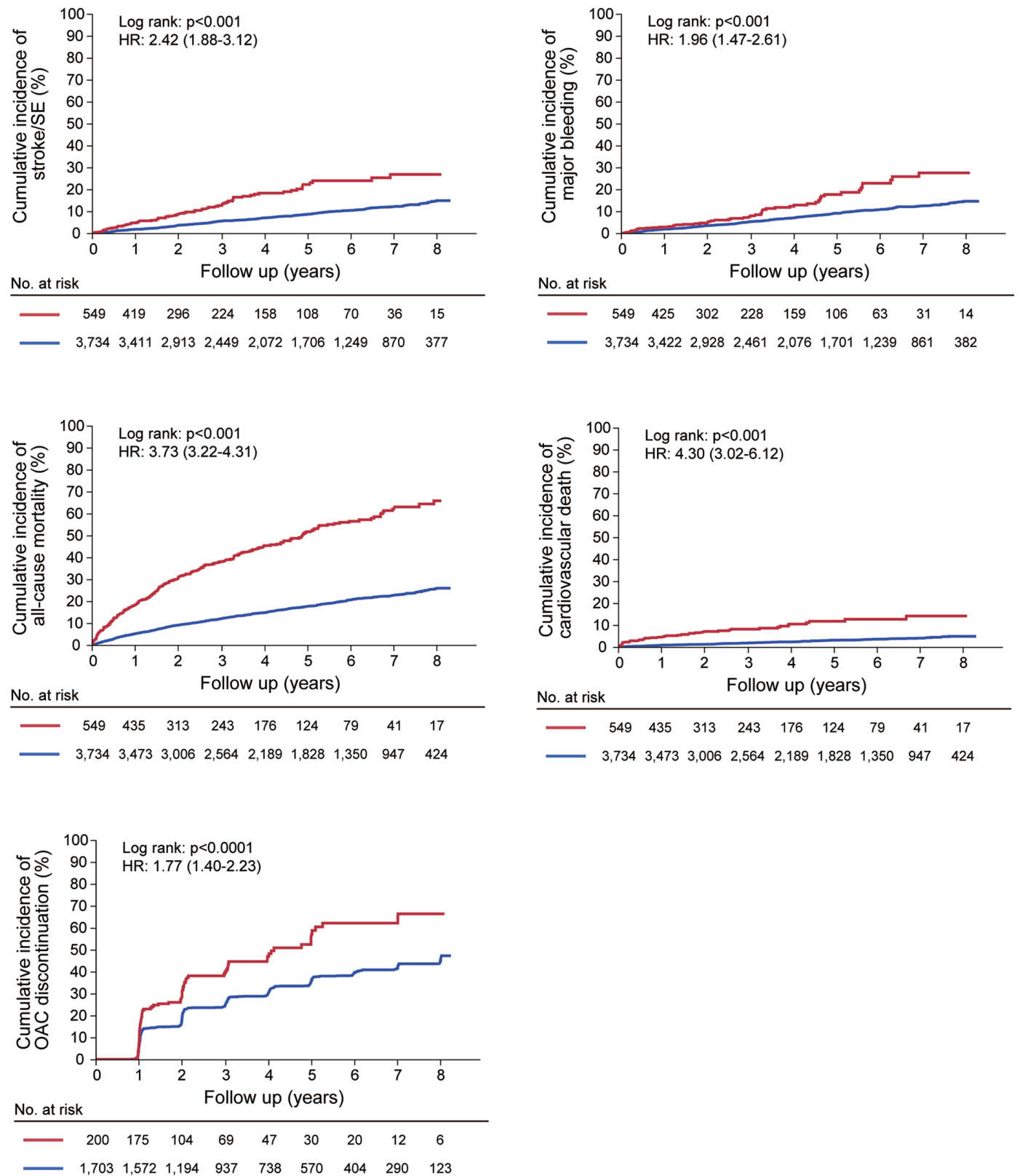

Figure 2. Kaplan-Meier curves for the incidences of stroke/systemic embolism (SE), major bleeding, all-cause mortality, cardiovascular death, and oral anticoagulant (OAC) discontinuation in the entire cohort: comparisons between ELDERCARE-eligible and non-eligible patients. Values in parentheses after hazard ratios (HRs) are 95\% confidence intervals.

patients from the Fushimi AF Registry, using the same criteria as the ELDERCARE-AF trial, namely patients with NVAF who were aged $\geq 80$ years, had a $\mathrm{CHADS}_{2}$ score $\geq 2$, and had $\geq 1$ risk factors for bleeding on $\mathrm{OAC}$ therapy, including low creatinine clearance $(15-30 \mathrm{~mL} / \mathrm{min})$, a history of bleeding from a critical area or organ, low body weight $(\leq 45 \mathrm{~kg}$ ), current use of antiplatelet drugs (for a purpose other than prophylaxis of cardioembolic stroke), or continuous use of NSAIDs. ${ }^{8}$ The Fushimi AF Registry does not collect data about the continuous use of NSAIDs; thus, we evaluated the bleeding risks other than the continuous use of NSAIDs. With regard to the "current use of antiplatelet drugs", patients receiving antiplatelet drugs who had concomitant coronary artery disease or peripheral artery disease were included in the present study. 


\begin{tabular}{|c|c|c|c|c|c|}
\hline & $\begin{array}{l}\text { ELDERCARE } \\
\text { eligible } \\
(n=549)\end{array}$ & $\begin{array}{c}\text { Non-eligible } \\
\text { (entire cohort; } \\
n=3,734)\end{array}$ & $P$ value ${ }^{A}$ & $\begin{array}{c}\text { Non-eligible } \\
(\geq 80 \text { years, } \\
\left.\text { CHADS }_{2} \geq 2 ; n=488\right)\end{array}$ & P value ${ }^{B}$ \\
\hline Stroke/SE & $74(4.8)$ & $327(2.0)$ & $<0.001$ & $52(2.9)$ & 0.009 \\
\hline Stroke & $72(4.7)$ & $316(1.9)$ & $<0.001$ & $51(2.9)$ & 0.012 \\
\hline SE & $2(0.1)$ & $13(0.1)$ & 0.529 & $1(0.1)$ & 0.517 \\
\hline Major bleeding & $55(3.6)$ & $314(1.9)$ & $<0.001$ & $54(3.1)$ & 0.340 \\
\hline Intracranial & $18(1.2)$ & $106(0.6)$ & 0.022 & $23(1.3)$ & 0.676 \\
\hline Others & $38(2.5)$ & 217 (1.3) & $<0.001$ & $31(1.7)$ & 0.102 \\
\hline All-cause mortality & $254(15.5)$ & 679 (3.9) & $<0.001$ & $157(8.4)$ & $<0.001$ \\
\hline Cardiovascular death & $45(2.7)$ & $105(0.6)$ & $<0.001$ & $26(1.4)$ & 0.011 \\
\hline Non-cardiovascular death & $209(12.7)$ & 574 (3.3) & $<0.001$ & $131(7.0)$ & $<0.001$ \\
\hline OAC discontinuation & $83(15.8)$ & $551(8.5)$ & $<0.001$ & $77(10.3)$ & 0.007 \\
\hline
\end{tabular}

\begin{tabular}{|c|c|c|c|c|c|}
\hline & \multicolumn{2}{|c|}{ ELDERCARE eligible } & \multirow[b]{2}{*}{ P value ${ }^{c}$} & \multicolumn{2}{|c|}{ ELDERCARE-AF trialD } \\
\hline & $\begin{array}{l}\text { OAC(+) } \\
(n=268)\end{array}$ & $\begin{array}{l}\text { OAC(-) } \\
(n=278)\end{array}$ & & $\begin{array}{c}\text { Edoxaban, } 15 \mathrm{mg} \\
(\mathrm{n}=492)\end{array}$ & $\begin{array}{l}\text { Placebo } \\
(n=492)\end{array}$ \\
\hline Stroke/SE & $42(5.3)$ & $32(4.3)$ & 0.396 & $15(2.3)$ & $44(6.7)$ \\
\hline Stroke & $42(5.3)$ & $30(4.0)$ & 0.263 & $12(1.8)$ & $40(6.0)$ \\
\hline SE & $0(0)$ & $2(0.3)$ & 0.135 & $3(0.4)$ & $6(0.9)$ \\
\hline Major bleeding & $28(3.4)$ & $26(3.6)$ & 0.849 & $20(3.3)$ & $11(1.8)$ \\
\hline Intracranial & $10(1.2)$ & $8(1.0)$ & 0.780 & $2(0.3)$ & $4(0.6)$ \\
\hline Others & $19(2.3)$ & $18(2.5)$ & 0.750 & $19(N / A)$ & $7(\mathrm{~N} / \mathrm{A})$ \\
\hline All-cause mortality & $119(13.7)$ & $134(17.4)$ & 0.080 & $66(9.9)$ & $69(10.2)$ \\
\hline Cardiovascular death & $25(2.9)$ & $20(2.6)$ & 0.647 & $41(\mathrm{~N} / \mathrm{A})$ & 41 (N/A) \\
\hline Non-cardiovascular death & $94(10.9)$ & $114(14.8)$ & 0.032 & $25(N / A)$ & $28(N / A)$ \\
\hline OAC discontinuation & & & & & \\
\hline
\end{tabular}

Unless indicated otherwise, data are given as $\mathrm{n}$ (\% per person-year). ${ }^{\mathrm{A} E L D E R C A R E}$ eligible vs. non-eligible (entire cohort). ${ }^{\mathrm{B}} \mathrm{ELDERCARE}$ eligible vs. non-eligible (age 80 years, CHADS2 score $\geq 2$ ). ${ }^{C}$ Those using oral anticoagulants $(\mathrm{OAC}(+))$ compared with those not using OAC $(\mathrm{OAC}(-))$ among ELDERCARE-eligible patients. ${ }^{\mathrm{D} D a t a}$ are from Okumura et al. ${ }^{8} \mathrm{~N} / \mathrm{A}$, not available; SE, systemic embolism.

\section{Endpoints and Definitions}

The endpoints in this study were the incidences of stroke or SE, major bleeding, all-cause mortality, and cardiovascular death. We also evaluated the discontinuation rates of $\mathrm{OAC}$ therapy in patients receiving OAC at baseline. Stroke was defined as the sudden onset of a focal neurologic deficit in a location consistent with the territory of a major cerebral artery, and the diagnosis of ischemic or hemorrhagic stroke was confirmed by computed tomography or magnetic resonance imaging. SE was defined as an acute vascular occlusion of an extremity or organs. Major bleeding was defined based on the criteria of the International Society on Thrombosis and Haemostasis as a reduction in the hemoglobin level by at least $2 \mathrm{~g} / \mathrm{dL}$, the transfusion of at least 2 units of blood, or symptomatic bleeding in a critical area or organ. ${ }^{11}$ Causes of death were adjudicated after consideration of all the available information, as reported previously. ${ }^{12}$

\section{Statistical Analysis}

Continuous variables are expressed as the mean $\pm \mathrm{SD}$ and categorical variables are presented as numbers and percentages. Continuous variables were compared using Student's t-test for normally distributed variables or the Wilcoxon rank-sum test for non-normally distributed variables. Categorical variables were compared using the Chi-squared test when appropriate; otherwise, Fisher's exact test was used. The cumulative incidence of clinical outcomes was estimated by the Kaplan-Meier method, and the significance of differences was assessed using the log-rank test. In addition, multivariable Cox proportional hazard models were used to estimate hazard ratios (HRs) and their 95\% confidence intervals (CIs) to evaluate which of the 4 bleeding risk factors were clinically relevant.

All analyses were performed using JMP version 14 (SAS Institute, Cary, NC, USA). Two-sided $\mathrm{P}<0.05$ was considered significant.

\section{Results}

Follow-up data were available for 4,375 patients with NVAF, and 92 patients were excluded because of incomplete data entry. Therefore, 4,283 patients with NVAF were analyzed in the present study. The median follow-up period was 1,517 days (interquartile range 740-2,550 days). Of the 4,283 patients with NVAF, 1,233 were aged $\geq 80$ years $(28.8 \%$ of the entire cohort; Figure 1A). The number of patients with a $\mathrm{CHADS}_{2}$ score $\geq 2$ was 1,037 , accounting for $84.1 \%$ of patients aged $\geq 80$ years (Figure 1B). The distribution of bleeding risk factors among patients aged $\geq 80$ years with a CHADS $_{2}$ score $\geq 2$ is shown in Figure 1C: $29.1 \%$ had low body weight $(\leq 45 \mathrm{~kg}), 19.1 \%$ had low creatinine clearance 


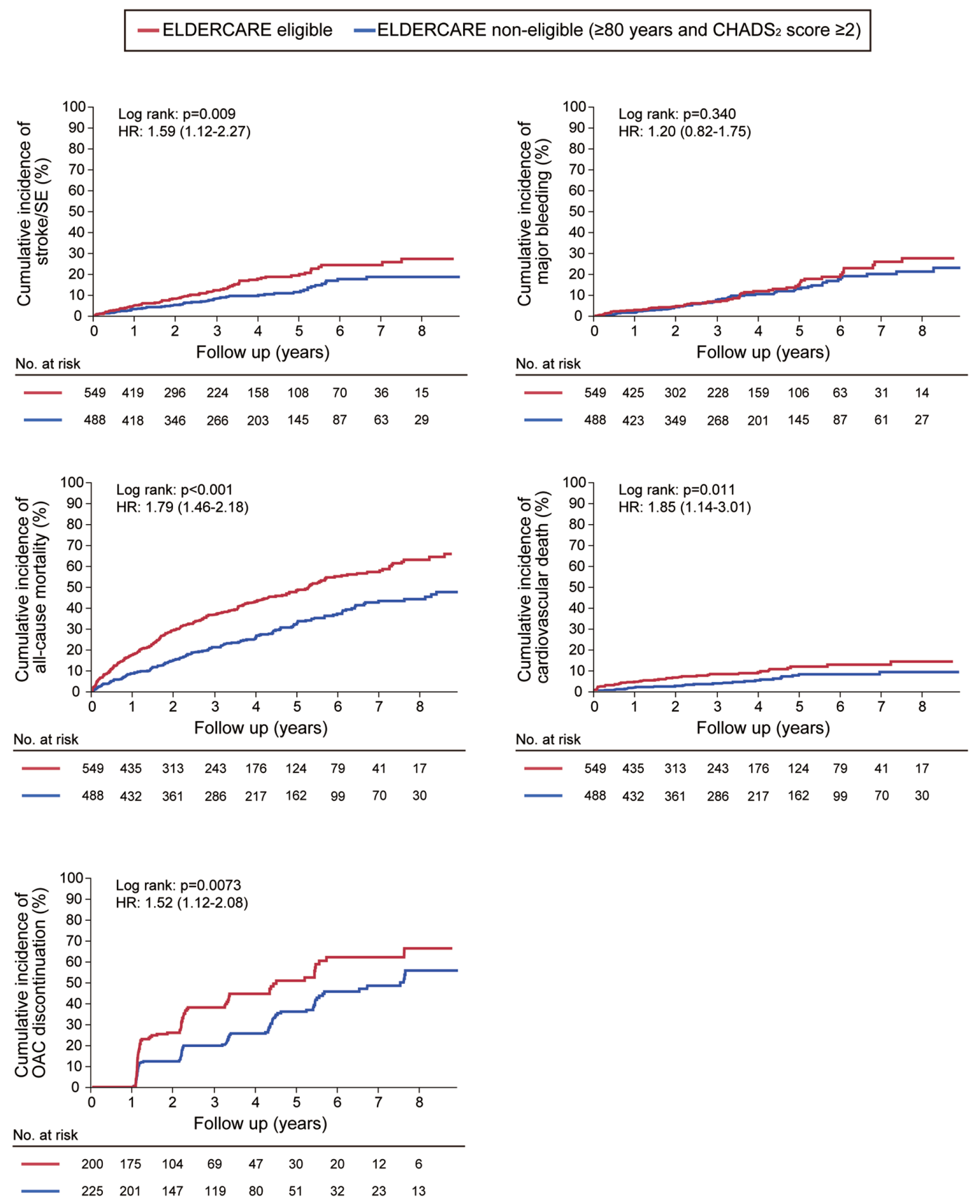

Figure 3. Kaplan-Meier curves for the incidence of stroke/systemic embolism (SE), major bleeding, all-cause mortality, cardiovascular death, and oral anticoagulant (OAC) discontinuation among patients aged $\geq 80$ years with a CHADS2 Score $\geq 2$ : comparisons between ELDERCARE-eligible and non-eligible patients. Values in parentheses after hazard ratios (HRs) are 95\% confidence intervals.

$(15-30 \mathrm{~mL} / \mathrm{min}), 16.7 \%$ were receiving antiplatelet drugs for the treatment of concomitant coronary artery disease or peripheral artery disease, and $6.4 \%$ had a history of bleeding in a critical area or organ. Consequently, ELDERCAREeligible patients $(\mathrm{n}=549)$ accounted for $12.8 \%$ of patients in the entire cohort and for $52.9 \%$ of patients aged $\geq 80$ years with a CHADS 2 score $\geq 2$ (Figure 1D).

The baseline characteristics of ELDERCARE-eligible and non-eligible patients are presented in Table 1. Compared with non-eligible patients in the entire cohort $(n=3,734)$, ELDERCARE-eligible patients were less often male (32.1\% vs. $64.7 \% ; \mathrm{P}<0.001$ ), older (mean age 86.2 vs. 71.4 years; $\mathrm{P}<0.001$ ), and had more comorbidities and higher risk scores (CHADS 2 , 3.2 vs. 1.8; $\mathrm{CHA}_{2} \mathrm{DS}_{2}$-VASc, 5.1 vs. 3.1; HAS-BLED 2.4 vs. 1.6 ; all $\mathrm{P}<0.001$ ). Compared with noneligible patients aged $\geq 80$ years with a $\mathrm{CHADS}_{2}$ score $\geq 2$ 


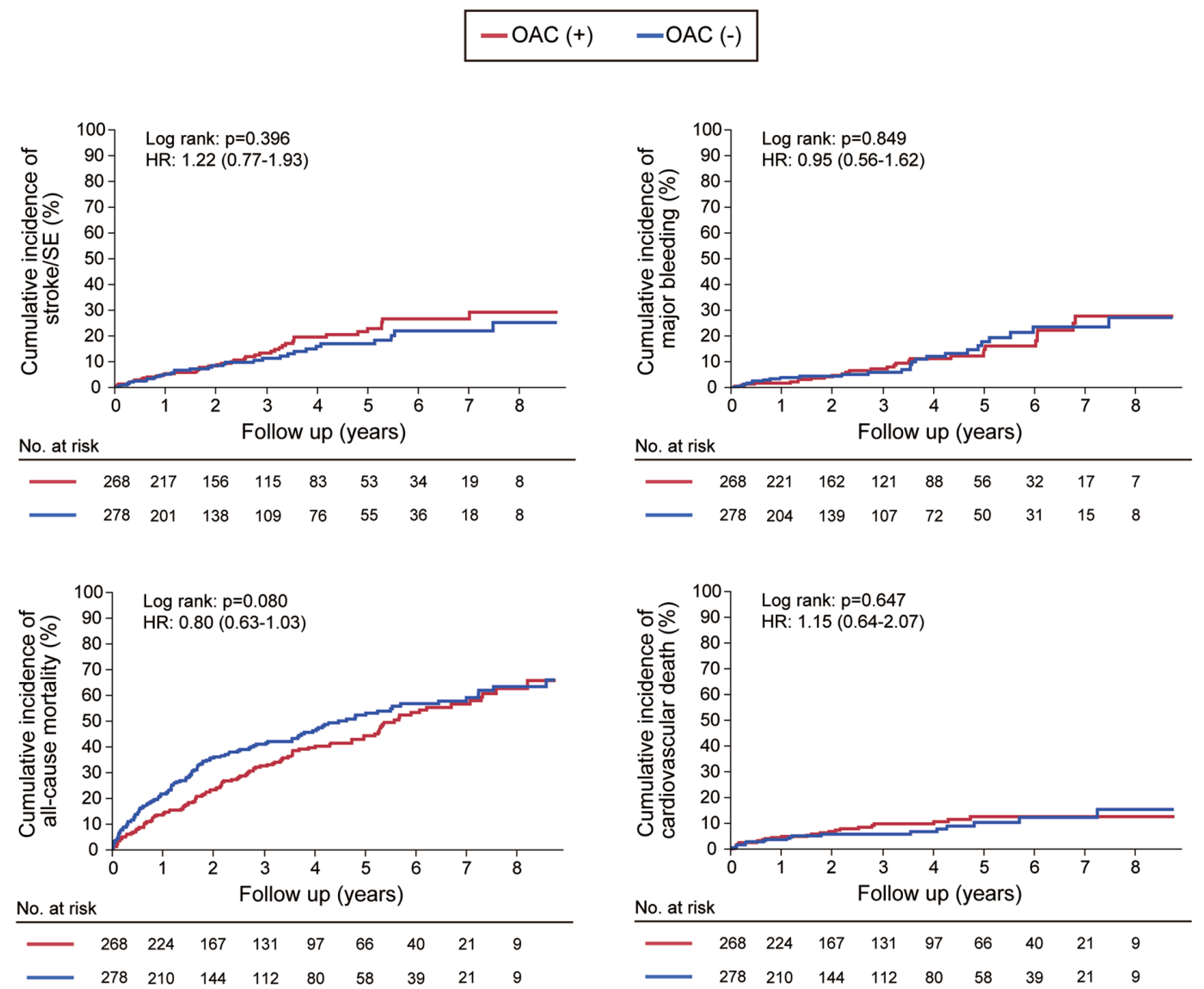

Figure 4. Kaplan-Meier curves for the incidence of stroke/systemic embolism (SE), major bleeding, all-cause mortality, and cardiovascular death in ELDERCARE-eligible patients: comparison between patients with and without oral anticoagulants (OACs). Values in parentheses after hazard ratios (HRs) are 95\% confidence intervals.

( $\mathrm{n}=488)$, ELDERCARE-eligible patients were also less often male $(32.1 \%$ vs. $57.2 \% ; \mathrm{P}<0.001)$, and had more comorbidities and higher risk scores $\left(\mathrm{CHADS}_{2}, 3.2\right.$ vs. 2.9; $\mathrm{CHA}_{2} \mathrm{DS}_{2}$-VASc, 5.1 vs. 4.4; HAS-BLED 2.4 vs. 1.9; all $\mathrm{P}<0.01)$.

The proportion of eligible patients receiving $\mathrm{OAC}$ at baseline was lower than the proportion of non-eligible patients in the entire cohort and non-eligible patients aged $\geq 80$ years with a $\mathrm{CHADS}_{2}$ score $\geq 2(48.8 \%$ vs. $55.8 \%$ and $61.7 \%$, respectively; $\mathrm{P}<0.01$ for both).

\section{Descriptive Comparisons With the ELDERCARE-AF Trial}

ELDERCARE-eligible patients in the Fushimi AF Registry had similar clinical backgrounds to those in the ELDERCARE-AF trial, including age (86.2 vs. 86.6 years, respectively), the proportion of males (32.1\% vs. $42.6 \%$, respectively), creatinine clearance $(33.0$ vs. $36.3 \mathrm{~mL} / \mathrm{min}$, respectively), $\mathrm{CHADS}_{2}$ score (3.2 vs. 3.1, respectively), $\mathrm{CHA}_{2} \mathrm{DS}_{2}$-VASc score (5.1 vs. 4.9 , respectively), and HASBLED score ( 2.4 vs. 2.3 respectively). Of the 4 bleeding risk factors, low body weight was the most prevalent in the Fushimi AF Registry (55.0\%), but the use of antiplatelet drugs was the most common bleeding risk factor in the ELDERCARE-AF trial (53.8\%).

\section{Clinical Outcomes}

As indicated in Figure 2 and Table 2, ELDERCARE-eligible patients had a significantly higher (all log-rank $\mathrm{P}<0.001$ ) incidence of stroke/SE (4.8\% vs. $2.0 \%$ per patient-year), major bleeding (3.6\% vs. $1.9 \%$ per patient-year), all-cause mortality ( $15.5 \%$ vs. $3.9 \%$ per patient-year), and cardiovascular death (2.7\% vs. $0.6 \%$ per patient-year) than non-eligible patients in the entire cohort. Discontinuation rates of OAC therapy were significantly higher in ELDERCARE-eligible than non-eligible patients ( $15.8 \%$ vs. $8.5 \%$ per patient-year; log-rank $\mathrm{P}<0.001)$.

Compared with non-eligible patients aged $\geq 80$ years with a $\mathrm{CHADS}_{2}$ score $\geq 2$, the incidence of stroke/SE, allcause mortality, and cardiovascular death, and the discontinuation rates of OAC therapy, remained significantly higher in ELDERCARE-eligible patients (stroke/SE, 4.8\% vs. $2.9 \%$ [log-rank $\mathrm{P}=0.009]$; all-cause mortality, $15.5 \%$ vs. $8.4 \%[\mathrm{P}<0.001]$; cardiovascular death, $2.7 \%$ vs. $1.4 \%$ $[\mathrm{P}=0.011]$; discontinuation of OAC therapy, $15.5 \%$ vs. $10.3 \%$ $[\mathrm{P}=0.007]$; Table 2; Figure 3). However, the incidence of major bleeding was not significantly different between ELDERCARE-eligible and non-eligible patients (3.6\% vs. $3.1 \%$, respectively; $\mathrm{P}=0.340$ ).

Among the ELDERCARE-eligible patients, the baseline 


\section{A Hazard ratios for stroke/SE}

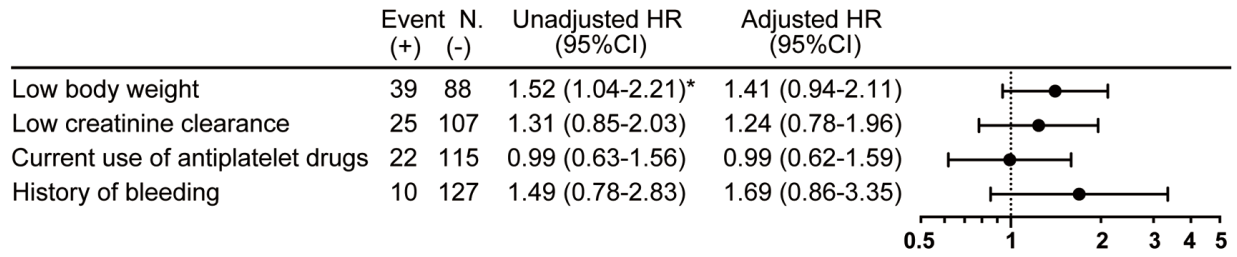

\section{B Hazard ratios for major bleeding}

\begin{tabular}{lccccc}
\multicolumn{7}{c}{$\begin{array}{c}\text { Event } \mathrm{N} \\
(+)\end{array}$} & $\begin{array}{c}\text { Unadjusted HR } \\
(-)\end{array}$ & $\begin{array}{c}\text { Adjusted HR } \\
(95 \% \mathrm{Cl})\end{array}$ \\
\hline Low body weight & 22 & 90 & $0.86(0.54-1.38)$ & $0.77(0.78-2.18)$ \\
Low creatinine clearance & 16 & 97 & $0.99(0.58-1.68)$ & $1.12(0.64-1.94)$ \\
Current use of antiplatelet drugs & 15 & 102 & $0.77(0.45-1.32)$ & $0.80(0.46-1.38)$ \\
History of bleeding & 12 & 106 & $2.34(1.29-4.26)^{* *}$ & $2.46(1.28-4.74)^{*}$
\end{tabular}

\section{Hazard ratios for all-cause mortality}

\begin{tabular}{lccccc} 
& $\begin{array}{c}\text { Event } \mathrm{N} . \\
(+)\end{array}$ & $\begin{array}{c}\text { Unadjusted HR } \\
(95 \% \mathrm{Cl})\end{array}$ & $\begin{array}{c}\text { Adjusted HR } \\
(95 \% \mathrm{Cl})\end{array}$ \\
\hline Low body weight & 135 & 257 & $2.00(1.64-2.45)^{* * *}$ & $1.85(1.49-2.28)^{* * *}$ \\
Low creatinine clearance & 102 & 325 & $1.76(1.41-2.21)^{* * *}$ & $1.49(1.18-1.89)^{* * *}$ \\
Current use of antiplatelet drugs & 70 & 365 & $1.00(0.77-1.29)$ & $0.98(0.76-1.29)$ \\
History of bleeding & 30 & 406 & $1.40(0.97-2.03)$ & $1.44(0.96-2.17)$ \\
& & & & $\mathbf{0 . 5}$ & $\mathbf{2}$
\end{tabular}

\section{Hazard ratios for cardiovascular death}

\begin{tabular}{|c|c|c|c|c|c|c|}
\hline & $\begin{array}{c}\text { Ever } \\
(+)\end{array}$ & it $N$ & $\begin{array}{c}\text { Unadjusted HR } \\
(95 \% \mathrm{Cl})\end{array}$ & $\begin{array}{c}\text { Adjusted HR } \\
(95 \% \mathrm{Cl})\end{array}$ & & \\
\hline Low body weight & 28 & 42 & $2.17(1.34-3.51)^{\star \star}$ & $1.93(1.17-3.19)^{*}$ & & + \\
\hline Low creatinine clearance & 21 & 53 & $2.16(1.30-3.59)^{\star *}$ & $1.80(1.05-3.09)^{*}$ & & \\
\hline Current use of antiplatelet drugs & 14 & 60 & $1.21(0.68-2.17)$ & $1.09(0.59-2.00)$ & & -1 \\
\hline History of bleeding & 5 & 69 & $1.31(0.53-3.24)$ & $1.64(0.66-4.10)$ & $\longmapsto$ & -1 \\
\hline
\end{tabular}

Figure 5. Hazard ratios (HRs) and $95 \%$ confidence intervals (Cls) for adverse events: (A) stroke/systemic embolism (SE), (B) major bleeding, (C) all-cause mortality, and (D) cardiovascular death. ${ }^{*} P<0.05,{ }^{*} P<0.01,{ }^{*} * \mathrm{P}<0.001$. Low body weight was defined as body weight $\leq 45 \mathrm{~kg}$ and low creatinine clearance $(\mathrm{CrCl})$ was defined as $15 \mathrm{~mL} / \mathrm{min} \leq \mathrm{CrCl}<30 \mathrm{~mL} / \mathrm{min}$.

characteristics of those receiving OACs were similar to those not receiving OAC, with the exception of more sustained AF $(64.9 \%$ vs. $42.5 \%$; $<<0.001)$ and a history of stroke $(40.7 \%$ vs. $28.1 \%$; $\mathrm{P}<0.001)$ in those with than without OACs (Supplementary Table). The incidence of both stroke/SE and major bleeding was comparable between patients with and without OACs (stroke/SE, 5.3\% vs. $4.3 \%$ $[\mathrm{P}=0.396]$; major bleeding, $3.4 \%$ vs. $3.6 \%[\mathrm{P}=0.849]$; Figure 4; Table 2).

We examined the association of each of the 4 bleeding risk factors with the incidence of stroke/SE, major bleeding, all-cause mortality, and cardiovascular death (Figure 5). The incidence of major bleeding was associated with history of bleeding (adjusted HR 2.46; 95\% CI 1.28-4.74; $\mathrm{P}=0.017$ ). Low body weight and low creatinine clearance were significantly associated with the incidence of all-cause mortality (adjusted HR 1.85 [95\% CI 1.49-2.28; $\mathrm{P}=0.011]$ and 1.49 [95\% CI $1.18-1.89 ; \mathrm{P}=0.001]$, respectively) and cardiovascular death (adjusted HR 1.93 [95\% CI 1.173.19; $\mathrm{P}<0.001$ ] and 1.80 [95\% CI 1.05-3.09; $\mathrm{P}=0.034$ ], respectively). On univariate analysis, low body weight was associated with the incidence of stroke/SE, but none of the 4 bleeding risk factors was significantly associated with stroke/SE after multivariate adjustment.

\section{Discussion}

The major findings of the present analysis of a large community-based cohort are that: (1) patients who met the inclusion criteria of the ELDERCARE trial were com- 
mon, accounting for $12.8 \%$ of the entire cohort and for $52.8 \%$ of patients aged $\geq 80$ years with a $\mathrm{CHADS}_{2}$ score $\geq 2$; (2) at baseline, ELDERCARE-eligible patients had a higher incidence than non-eligible patients of stroke/SE, major bleeding, and all-cause and cardiovascular mortality, with the subgroup of elderly patients aged $\geq 80$ years with a $\mathrm{CHADS}_{2}$ score $\geq 2$ having a higher incidence of stroke/SE and all-cause and cardiovascular mortality than non-eligible patients, but a comparable incidence of major bleeding; and (3) of the 4 bleeding risk factors, low body weight and low creatinine clearance were associated with all-cause and cardiovascular mortality, and history of bleeding was associated with major bleeding.

The ELDERCARE-AF trial demonstrated that lowdose edoxaban (15 mg, once daily) prevented stroke or SE in very elderly Japanese patients with NVAF in whom standard OAC therapy was considered not appropriate because of bleeding risks. ${ }^{8}$ Our present analysis shows that patients who would have been considered eligible for the ELDERCARE-AF trial are common in contemporary community-based clinical practice, accounting for nearly half the NVAF patients aged $\geq 80$ years. Due to high bleeding risks with OAC therapy, these patients were less often prescribed OAC therapy at baseline, and discontinuation rates of OAC therapy were significantly higher. These data clearly demonstrate that OAC therapy was likely to be withheld in these patients and support the potential usefulness of even prescribing low-dose edoxaban for such patients, rather than leaving them patients untreated, on the basis of evidence from the ELDERCARE-AF trial.

Because there is a significant overlap between the risk of thromboembolism and that of bleeding, the ELDERCAREeligible patients defined on the basis of high bleeding risks had a higher incidence of stroke/SE and higher mortality than non-eligible patients. However, compared with noneligible patients aged $\geq 80$ years with a $\mathrm{CHADS}_{2}$ score $\geq 2$, the incidence of major bleeding was comparable between eligible and non-eligible patients. The lack of difference in bleeding between eligible and non-eligible patients may suggest the possibility that the higher rate of prescription of OACs to non-eligible patients may have abolished any potential difference.

Comparing the present study with the ELDERCARE-AF trial, ${ }^{8}$ the ELDERCARE-eligible patients in the present study had a broadly similar clinical background to patients in the ELDERCARE-AF trial, including age, sex, creatinine clearance, and $\mathrm{CHADS}_{2}, \mathrm{CHA}_{2} \mathrm{DS}_{2}-\mathrm{VASc}$, and HASBLED scores. However, mortality was lower among the trial patients than among eligible patients in the present study, and the incidence of major bleeding in the placebo group in the trial was lower than that among eligible patients without OACs in the present study. Because there were no exclusion criteria in our registry and the trial was a randomized clinical trial with a highly selected population, this may have led to differences between the realworld, community-based population in the present study and the ELDERCARE-AF trial population, which may have contributed to the differences in results: patients with a poorer condition or those with social problems, such as the solitary aged person and "elder care by the elderly", may have been excluded from the trial. In addition, the baseline characteristics and the incidence of stroke/SE and major bleeding were comparable between patients with and without OAC among the ELDERCARE-eligible patients in our Registry. Because warfarin was the predominant OAC therapy in the present study, underdosing, poor adherence, or low time in the therapeutic range of warfarin may have contributed to the results. Some of the ELDERCAREeligible patients may not have received OAC therapy due to a high bleeding risk, frailty, or social reasons, which could have also affected the results.

The 4 bleeding risk factors may have differential effects on outcomes. As we reported previously, both low body weight and renal impairment were associated with stroke/ SE and all-cause mortality among Japanese AF patients enrolled in the Fushimi AF Regisry. ${ }^{13,14}$ In the present study, we further demonstrated that low body weight and renal impairment were associated with all-cause mortality and cardiovascular death in the ELDERCARE-eligible population of the same Registry; however, none of the 4 bleeding risk factors was significantly associated with stroke/SE after multivariate adjustment. In addition, the AFIRE (Atrial Fibrillation and Ischemic Events with Rivaroxaban in Patients with Stable Coronary Artery Disease) trial demonstrated that anticoagulant monotherapy was non-inferior for efficacy and superior for safety to combination therapy with an anticoagulant and antiplatelet drug in patients with AF and stable coronary artery disease. ${ }^{15}$ Therefore, the number of AF patients requiring the continuous long-term use of antiplatelet drugs will hopefully decrease over time, especially because such combination therapy over 1 year is not recommended in current clinical guidelines. ${ }^{\mathbf{5 , 6}}$

\section{Study Limitations}

This study has several limitations. First, the results were derived from a prospective observational study. Therefore, we can only show associations and not causality, with limitations inherent to this design, such as selection bias and unmeasured confounders. Second, no data were available regarding the continuous use of NSAIDs, and we were not able to evaluate the association between this bleeding risk factor and outcomes. Third, we selected ELDERCAREeligible or non-eligible patients based on clinical characteristics at the time of enrollment. So, changes in the characteristics during follow-up were not considered. Fourth, in this study warfarin was the predominant OAC therapy, because direct OACs (DOACs) were unavailable when the Registry was started in 2011. The statistical analysis was based only on OAC usage at the time of enrollment. This did not take into account the initiation, adherence, and switching of OACs, or the quality of the adjustment, such as time spent in the therapeutic range for patients taking warfarin, through the follow-up period. In addition, we have no data regarding reasons for discontinuing OAC therapy. Given the overall superiority of DOAC over warfarin, ${ }^{8,16-19}$ the results of the study may differ now that DOACs are increasingly used in clinical practice.

\section{Conclusions}

We showed that patients with NVAF who met the inclusion criteria of the ELDERCARE-AF trial are common in the contemporary, community-based, routine practice and had high risks of stroke/SE, major bleeding, and all-cause and cardiovascular mortality.

\section{Acknowledgments}

The authors sincerely appreciate the help of all the institutions participating in the Fushimi AF Registry and the clinical research coor- 
dinators (T. Shinagawa, M. Mitamura, M. Fukahori, M. Kimura, M. Fukuyama, C. Kamata, and N. Nishiyama). The Fushimi AF Registry is supported, in part, by the Practical Research Project for Life-Style Related Diseases Including Cardiovascular Diseases and Diabetes Mellitus from Japan Agency for Medical Research and Development (AMED; 19ek0210082 h0003, 18ek0210056h0003).

The Fushimi AF Registry is supported by research funding from Boehringer Ingelheim, Bayer Healthcare, Pfizer, Bristol-Myers Squibb, Astellas Pharma, AstraZeneca, Daiichi Sankyo, Novartis Pharma, MSD, Sanofi-Aventis, and Takeda Pharmaceutical.

\section{Contributors}

Y.I. analyzed the data and wrote the paper. H.O., K.I., S.I., K.D., Y.H., A.F., Y.A., M. Ishii, M. Iguchi, N.M., M.E., H.T., H.W., K.H., M. Abe contributed to the acquisition of data, and helped data analysis and interpretation. M. Akao is a principal investigator of the Fushimi AF Registry, and the corresponding author of this paper. G.Y.H.L. and M. Akao are joint senior authors of this paper.

\section{Sources of Funding}

This study did not receive any specific funding.

\section{Disclosures}

M. Akao has received lecture fees from Pfizer, Bristol-Myers Squibb, Boehringer Ingelheim, Bayer Healthcare, and Daiichi Sankyo. G.Y.H.L. has acted as a consultant for Bayer/Janssen, BMS/Pfizer, Biotronik, Medtronic, Boehringer Ingelheim, Novartis, Verseon, and Daiichi-Sankyo and as a speaker for Bayer, BMS/Pfizer, Medtronic, Boehringer Ingelheim, and Daiichi-Sankyo, but has not directly received any fees personally. The remaining authors have no relationships relevant to the contents of this paper to disclose.

\section{IRB Information}

The study protocol was approved by the ethics committees of the National Hospital Organization Kyoto Medical Center and Ijinkai Takeda General Hospital (Reference no. 10-058 and 14-033, respectively).

\section{Data Availability}

The deidentified participant data will not be shared.

\section{References}

1. Wolf PA, Abbott RD, Kannel WB. Atrial fibrillation: A major contributor to stroke in the elderly. The Framingham Study. Arch Intern Med 1987; 147: 1561-1564.

2. Lip GYH, Clementy N, Pericart L, Banerjee A, Fauchier L. Stroke and major bleeding risk in elderly patients aged $\geq 75$ years with atrial fibrillation: The Loire Valley atrial fibrillation project. Stroke 2015; 46: $143-150$.

3. Patti G, Lucerna M, Pecen L, Siller-Matula JM, Cavallari I, Kirchhof $\mathrm{P}$, et al. Thromboembolic risk, bleeding outcomes and effect of different antithrombotic strategies in very elderly patients with atrial fibrillation: A sub-analysis from the PREFER in AF (PREvention oF Thromboembolic Events-European Registry in Atrial Fibrillation). J Am Heart Assoc 2017; 6: e005657.

4. January CT, Wann LS, Calkins H, Chen LY, Cigarroa JE, Cleveland JC Jr, et al. Correction to: 2019 AHA/ACC/HRS Focused Update of the 2014 AHA/ACC/HRS guideline for the management of patients with atrial fibrillation: A report of the American College of Cardiology/American Heart Association Task Force on Clinical Practice Guidelines. Circulation 2019; 140: $125-151$.
5. Hindricks G, Potpara T, Dagres N, Arbelo E, Bax JJ, BlomströmLundqvist C, et al. 2020 ESC guidelines for the diagnosis and management of atrial fibrillation developed in collaboration with the European Association for Cardio-Thoracic Surgery (EACTS). Eur Heart J 2020; 42: 373-498.

6. JCS/JHRS 2020 guideline on pharmacotherapy of cardiac arrhythmias [in Japanese]. https://www.j-circ.or.jp/cms/wp-content/ uploads/2020/01/JCS2020_Ono.pdf (accessed March 3, 2021).

7. McCrory DC, Matchar DB, Samsa G, Sanders LL, Pritchett ELC. Physician attitudes about anticoagulation for nonvalvular atrial fibrillation in the elderly. Arch Intern Med 1995; 155: $277-281$.

8. Okumura K, Akao M, Yoshida T, Kawata M, Okazaki O, Akashi S, et al. Low-dose edoxaban in very elderly patients with atrial fibrillation. $N$ Engl J Med 2020; 383: 1735-1745.

9. Akao M, Chun YH, Wada H, Esato M, Hashimoto T, Abe M, et al. Current status of clinical background of patients with atrial fibrillation in a community-based survey: The Fushimi AF Registry. J Cardiol 2013; 61: 260-266.

10. Akao M, Chun YH, Esato M, Abe M, Tsuji H, Wada H, et al. Inappropriate use of oral anticoagulants for patients with atrial fibrillation: 1-year outcomes of the Fushimi AF Registry. Circ $J$ 2014; 78: 2166-2172.

11. Schulman S, Kearon C. Definition of major bleeding in clinical investigations of antihemostatic medicinal products in non-surgical patients. $J$ Thromb Haemost 2005; 3: 692-694.

12. An Y, Ogawa H, Yamashita Y, Ishii M, Iguchi M, Masunaga N, et al. Causes of death in Japanese patients with atrial fibrillation: The Fushimi Atrial Fibrillation Registry. Eur Heart J Qual Care Clin Outcomes 2019; 5: 35-42.

13. Hamatani Y, Ogawa H, Uozumi R, Iguchi M, Yamashita Y, Esato M, et al. Low body weight is associated with the incidence of stroke in atrial fibrillation patients: Insight from the Fushimi AF Registry. Circ J 2015; 79: 1009-1017.

14. Abe M, Ogawa H, Ishii M, Masunaga N, Esato M, Chun YH, et al. Relation of stroke and major bleeding to creatinine clearance in patients with atrial fibrillation (from the Fushimi AF Registry). Am J Cardiol 2017; 119: 1229-1237.

15. Yasuda S, Kaikita K, Akao M, Ako J, Matoba T, Nakamura M, et al. Antithrombotic therapy for atrial fibrillation with stable coronary disease. $N$ Engl J Med 2019; 381: 1103-1113.

16. Alexander JH, Andersson U, Lopes RD, Hijazi Z, Hohnloser $\mathrm{SH}$, Ezekowitz JA, et al. Apixaban $5 \mathrm{mg}$ twice daily and clinical outcomes in patients with atrial fibrillation and advanced age, low body weight, or high creatinine: A secondary analysis of a randomized clinical trial. JAMA Cardiol 2016; 1: 673-681.

17. Halvorsen S, Atar D, Yang H, De Caterina R, Erol C, Garcia D, et al. Efficacy and safety ofapixaban compared with warfarin according to age for stroke prevention in atrial fibrillation: Observations from the ARISTOTLE trial. Eur Heart J 2014; 35: $1864-1872$.

18. Hylek EM, Held C, Alexander JH, Lopes RD, De Caterina R, Wojdyla DM, et al. Major bleeding in patients with atrial fibrillation receiving apixaban or warfarin: The ARISTOTLE Trial (Apixaban for Reduction in Stroke and Other Thromboembolic Events in Atrial Fibrillation): Predictors, characteristics, and clinical outcomes. J Am Coll Cardiol 2014; 63: 2141-2147.

19. Kato ET, Giugliano RP, Ruff CT, Koretsune Y, Yamashita T, Kiss RG, et al. Efficacy and safety of edoxaban in elderly patients with atrial fibrillation in the ENGAGE AF-TIMI 48 Trial. $J \mathrm{Am}$ Heart Assoc 2016; 5: e003432.

\section{Supplementary Files}

Please find supplementary file(s);

http://dx.doi.org/10.1253/circrep.CR-21-0121 